\title{
Regulatory T cells in cutaneous immune responses.
}

$\operatorname{AUTHOR}(\mathrm{S})$ :

Honda, Tetsuya; Miyachi, Yoshiki; Kabashima, Kenji

CITATION:

Honda, Tetsuya ...[et al]. Regulatory T cells in cutaneous immune responses.. Journal of dermatological science 2011, 63(2): 75-82

ISSUE DATE:

2011-08

URL:

http://hdl.handle.net/2433/143738

RIGHT:

(c) 2011 Published by Elsevier Ireland Ltd.; この論文は出版社版でありま せん。引用の際には出版社版をご確認ご利用ください。; This is not the published version. Please cite only the published version. 


\title{
Regulatory $\mathbf{T}$ cells in cutaneous immune responses
}

\section{Tetsuya Honda, Yoshiki Miyachi, and Kenji Kabashima}

Department of Dermatology, Kyoto University Graduate School of Medicine, Kyoto

\author{
606-8507, Japan \\ Tel: $+81-75-751-3310$ \\ Fax: + 81-75-761-3002
}

Correspondence should be addressed to Dr. Kenji Kabashima or Dr. Tetsuya Honda

Department of Dermatology, Kyoto University Graduate School of Medicine, 54 Shogoin-Kawara, Sakyo, Kyoto 606-8507, Japan.

Tel: + 81-75-751-3310; Fax: + 81-75-761-3002; Email: kaba@kuhp.kyoto-u.ac.jp (KK) or hontetsu@kuhp.kyoto-u.ac.jp (TH) 


\section{Abstract}

Regulatory T cells (Treg) are a subset of T cells with strong immunosuppressive activity. In the skin, it has recently been revealed that Treg play important roles not only in the maintenance of skin homeostasis but also in the regulation of the immune responses, such as contact hypersensitivity and atopic dermatitis. Furthermore, the skin plays important roles in the induction of Treg in the periphery. In this review, we will provide an overview of the mechanism of Treg-mediated immunosuppression and discuss the role of Treg in the skin.

(88 words) 


\section{Contents}

Introduction

1. Mechanism of suppression by Treg

2. Characterization of Treg in the skin

3. Treg induction and expansion in the skin

4. Treg in CHS

5. Atopic dermatitis (AD) and Treg

Conclusion 


\section{Introduction}

Regulatory T cells (Treg) are a subset of T cells with strong immunosuppressive activity. Treg were originally identified as $\mathrm{CD} 4^{+} \mathrm{CD} 25^{+} \mathrm{T}$ cells [1] [2]. When mice were depleted of $\mathrm{CD} 4^{+} \mathrm{CD} 25^{+}$cells, they spontaneously developed autoimmune diseases and allergies, indicating that $\mathrm{CD} 4^{+} \mathrm{CD} 25^{+} \mathrm{T}$ cells are essential for the maintenance of self-tolerance. Later on, the forkhead box p3 (Foxp3) gene was identified as the master transcriptional factor of Treg [3].

There are at least two kinds of Foxp $3^{+}$Treg: naturally occurring Treg (nTreg) and inducible Treg (iTreg) [4]. nTreg develop in the thymus, and play an important role in the maintenance of self-tolerance and immune homeostasis. Scurfy mice, which possess a defective Foxp3 gene, exhibit hyperactivation of $\mathrm{CD}^{+} \mathrm{T}$ cells and overproduction of proinflammatory cytokines, and typically die within a month after birth [5]. Patients with IPEX syndrome (immune dysregulation polyendocrinopathy, enteropathy, $\mathrm{X}$-linked syndrome) have a mutation in the human FOXP3 gene, and are therefore regarded as the human counterpart of scurfy mice [6]. iTreg, on the other hand, are induced from naïve $\mathrm{T}$ cells in the presence of transforming growth factor (TGF)- $\beta$, and develop in the periphery. Retinoic acid facilitates the differentiation of naïve $\mathrm{T}$ cells to Foxp $3^{+}$Treg [7] [8] and may be related to the establishment of oral tolerance, although it remains to be determined whether iTreg are functionally stable and to what extent they contribute under physiological conditions.

In addition to Foxp $3^{+}$Treg, there are other types of Treg, such as $\operatorname{Tr} 1$ and Th3 cells; these are induced in the periphery [4] [9] [10]. Tr1 cells can be induced through the antigenic stimulation of naïve $\mathrm{T}$ cells in the presence of IL-10 in vitro, and exert a suppressive effect in vitro by inducing large amounts of IL-10 and TGF- $\beta$. Th3 cells 
produce TGF- $\beta$ in an antigen-specific manner, and exert a suppressive effect. Intriguingly, however, both are Foxp3 and CD25 negative. No further details of this population are discussed in this manuscript.

Evidence has accumulated regarding the regulatory roles of Treg not only in self-tolerance, but also in a variety of pathophysiological immune responses, such as gastritis [11], arthritis, encephalomyelitis [12], inflammatory bowel disease (IBD) [13], insulin-dependent diabetes [14] and various allergic skin diseases such as contact hypersensitivity or atopic dermatitis.

In this review, we will provide an overview of the mechanism of Treg-mediated immunosuppression, mainly focusing on Foxp $3^{+}$Treg, and discuss the role of Treg in the skin immune responses, focusing on contact hypersensitivity and atopic dermatitis.

\section{Mechanism of suppression by Treg}

Treg potently suppress the proliferation of $\mathrm{T}$ cells when Treg are co-cultured with responder cells that have been stimulated with a specific antigen or a polyclonal $\mathrm{T}$ cell receptor stimulator in vitro. Multiple suppression mechanisms have been proposed based on in vitro assays; for example, IL-10 [13], TGF- $\beta$ [15], and IL-35 [16] have been considered as possible soluble suppressive factors of $\mathrm{T}$ cell proliferation. Absorption of IL-2 by Treg may also be involved in inhibiting T cell proliferation [17]. It has also been reported that Treg exert their regulatory functions by cell-cell contact-dependent factors, such as CD39/CD73 [18] and granzyme/perforin [19]. In addition to these direct suppressive effects, Treg indirectly suppress $\mathrm{T}$ cell proliferation by affecting the function of APCs. It has been reported that Treg inhibited the T cell 
stimulatory capacity of APCs by down-regulating CD80 and CD86 expression through cytotoxic T-lymphocyte antigen (CTLA)-4 and lymphocyte function-associated antigen (LFA)-1 [20]. Using two-photon microscopic analysis, Tadokoro et al [21] and Tang et al [14] have revealed that Treg inhibit stable contact and interaction between APCs and effector $\mathrm{T}$ cells. Treg also stimulate DCs to express the enzyme indoleamine 2,3-dioxygenase (IDO), which catabolizes the conversion of tryptophan to kynurenine, a toxic factor to T cells [22]. In addition to their effect on APCs, it has also been reported that Treg down-regulate mast cell function by suppressing mast cell degranulation and anaphylactic response through OX40-OX40L interaction [23]. The mechanisms by which suppression is achieved may vary depending on context, however, and it has not yet been determined how these in vitro findings correlate with in vivo suppression.

\section{Characterization of Treg in the skin}

Treg exist in all non-lymphoid tissues; the skin has a particularly high proportion of Treg in the steady state $[24,25]$ [26]. Treg in the skin are CD $44^{+}$and CD103 ${ }^{\text {high }}[24,25]$ [26], and express the chemokine receptors CCR4, CCR5, CCR6 and CCR7. CCR5 ${ }^{+}$ Treg preferentially migrate to cutaneous lesions of Leishmania major infection [27]. Mice with a complete loss of CCR4 on Treg develop spontaneous lymphocytic infiltration and severe inflammation in the skin and lungs, accompanied by peripheral lymphadenopathy and increased differentiation of skin tropic $\mathrm{CD} 4^{+} \mathrm{Foxp} 3^{-} \mathrm{T}$ cells. Using $\alpha$-1,3-fucosyltransferase VII (Fut7) deficient mice, Dudda et al [26] have reported the importance of E- and P-selectin ligand for Treg migration to the skin. Loss of these selectin bindings caused skin-specific inflammation, indicating the essential role of skin-resident Treg for maintaining immune homeostasis locally. 


\section{Treg induction and expansion in the skin}

Ultraviolet (UV) radiation to the skin is well known to cause immunosuppression, and is accordingly applied as a treatment for a wide variety of skin diseases. Recently, it has been revealed that one of the immunosuppressive mechanisms involved in this effect is mediated by Treg, which are induced by UV irradiation [28]. It has been proposed that the cells responsible for this induction of Treg are epidermal Langerhans cells (LCs), an important group of skin-resident dendritic cells. Loser et al. [29] have reported that the receptor activator of NF-kappaB ligand (RANKL) was induced in keratinocytes by UV exposure, and RANKL-activated LCs were responsible for the development of UV-induced Treg. It has also been reported that the induction of Treg by UV irradiation was completely abolished by the depletion of LCs using Langerin-DTR mice or steroid mometasone [30] [31]. In addition, it has recently been reported that IL-10-producing and OX40 ligand-expressing mature LCs are responsible for the induction of Treg upon UV exposure [31], suggesting the importance of LCs for Treg induction. In addition to UV-induced immunosuppression, similar findings were observed concerning the mechanisms involved in immunosuppression during skin grafting. Yoshiki et al. [32] have reported that the development of contact hypersensitivity (CHS) was suppressed when mice were sensitized with a hapten through full-thickness grafted skin. In this model, $\mathrm{CD} 4^{+} \mathrm{CD} 25^{+}$but not $\mathrm{CD} 4^{+} \mathrm{CD} 25^{-} \mathrm{T}$ cells in draining lymph nodes (LNs) were responsible for this suppression. In addition, a high expression of RANKL was observed in the grafted skin, and recombinant RANKL stimulated LCs to produce IL-10. These findings suggest that the LCs play important roles in the peripheral induction of Treg. Recently, it has been reported that glucocorticoids modify LCs to produce TGF- $\beta$ 
and expand regulatory $\mathrm{T}$ cells in humans [33], implying that glucocorticosteroids may exert their anti-inflammatory functions by inducing Treg.

The phenotypes and suppression mechanisms of UV-induced Treg are different from those of nTreg. Schwartz et al. [34] [35] have reported that the administration of $\mathrm{CD} 4^{+} \mathrm{CD} 25^{+}$cells from UV-irradiated DNFB-sensitized mice impaired sensitization of CHS. These UV-induced Treg did not suppress the CHS response when administered before elicitation, though natural $\mathrm{CD} 4{ }^{+} \mathrm{CD} 25^{+}$Treg did. Direct injection of UV-induced Treg into the elicitation sites did suppress the CHS response, however. They accordingly concluded that UV-induced Treg did not express skin-homing receptors for E- and P-selectins, and so failed to suppress elicitation. In addition, they reported that UV-induced Treg changed APCs in LNs from a stimulatory to a regulatory phenotype by modulating the co-stimulatory molecules on APCs, which, in turn, further induce Treg [36].

Although the importance of LCs has been suggested as mentioned above, other groups have reported the importance of dermal DCs in UV-induced immunosuppression and peripheral Treg induction. Wang et al. [37] reported the UV-induced immunosuppression was abolished by selective depletion of Langerin-positive dermal DCs, suggesting the importance of Langerin-positive dermal DCs in Treg induction. It has also been reported that retinoic-acid producing CD103-negative dermal dendritic cells have the ability to induce Treg in draining LNs [38], in contrast to the equivalent phenomenon in the gut, where CD103-positive DCs are responsible for the induction of Treg [39] 


\section{Treg in CHS}

CHS, a frequently used mouse model of contact dermatitis, is a prototype of skin immune response, and the role of Treg in CHS has been gradually revealed.

The development of CHS is divided into two phases: sensitization and elicitation [40]. In the sensitization phase, low molecular weight compounds called haptens are cross-linked to epidermal proteins and taken up by resident DCs such as LCs and dermal DCs. Subsequently, these cells are matured by proinflammatory cytokines such as TNF- $\alpha$, IL-1 $\beta$, and prostaglandin $\mathrm{E}_{2}$, and migrate to the draining LNs to present antigens in a CCR7 and CXCR4-dependent manner [41, 42]. After antigen presentation, naive $\mathrm{T}$ cells are activated and differentiated into antigen-specific Th1 and Tc1 cells under the influence of polarizing signals such as IL-12 and other chemical mediators [43]. Th17 cells are also involved in the pathogenesis of CHS [44]. When the skin is re-exposed to the same hapten after establishment of the sensitization, an antigen-specific T cell-mediated inflammation that is known as elicitation phase is provoked. Upon re-exposure to the same hapten, keratinocytes and mast cells produce chemokines and pro-inflammatory cytokines such as TNF- $\alpha$ and IL-1 $\beta$, which activate endothelial cells and induce the expression of E- or P-selectins [45-47]. Then, neutrophils and antigen-specific $\mathrm{T}$ cells enter the dermis and release IFN- $\gamma$, which further stimulates keratinocytes to induce massive leukocyte infiltration [48].

\section{a. Treg in the CHS response - elicitation phase}

The effect of Treg on CHS has mainly been investigated in the elicitation phase. Ring et al. have purified $\mathrm{CD} 4^{+} \mathrm{CD} 25^{+}$Treg from naïve mice and administered them into TNCB-sensitized recipient mice intravenously one day before elicitation [49]. 
Administration of Treg significantly suppressed the ear swelling response and inflammatory cell infiltration into the skin compared to those of vehicle-treated mice. Ring et al. have reported that these suppressive effects are mediated by soluble factors, especially IL-10. Administration of a culture supernatant of Treg suppressed the CHS response, and this suppression was reversed by an anti-IL-10 Ab. Furthermore, Treg from IL-10-deficient mice failed to suppress the CHS response by inhibiting the leukocyte influx into the inflamed skin.

The same group has recently reported that the adenosine produced by Treg is involved in blocking the influx of leukocytes into the skin by downregulating E- and Pselectins on endothelial cells [50]. Adenosine triphosphate (ATP) is first degraded by CD39 to adenosine diphosphate (ADP) and then to adenosine monophosphate (AMP).

The AMP is serially dephosphorylated by CD73 to adenosine. Treg are strongly positive for both CD39 and CD73 expression; therefore, Treg convert ATP to adenosine and suppress the CHS response. On the other hand, conventional T cells exhibit only a low basal expression level of CD39. Accordingly, injection of adenosine or Treg abrogated the ear-swelling response in CHS, which was not seen using Treg from CD39-deficient mice [50]. Moreover, Treg further upregulate CD39 expression after activation; this activation is a prerequisite for Treg to acquire their suppressive capacity.

\section{b. Treg in the CHS response - sensitization phase}

While reports on the role of Treg in the sensitization phase have been rather limited compared to those discussing the elicitation phase, some interesting reports have recently been published. Dubois et al. [51], for example, have reported the involvement of Treg in the induction of oral tolerance and inhibition of DNFB-induced CHS. Oral tolerance was induced by feeding DNFB orally prior to DNFB sensitization. Although 
no such tolerance induction was seen in $\mathrm{CD}^{+} \mathrm{T}$ cell-deficient mice, transfer of naïve $\mathrm{CD} 4^{+} \mathrm{CD} 25^{+} \mathrm{T}$ cells restores oral tolerance in those mice, in a manner independent of IL-10 [51]. The same authors also showed that administration of neutralizing anti-CD25 monoclonal antibody (mAb) impairs oral tolerance in WT mice. Intriguingly, administration of anti-CD25 mAb before sensitization had no significant affect on the ear swelling response, suggesting that $\mathrm{CD} 4^{+} \mathrm{CD} 25^{+} \mathrm{T}$ cells are responsible for oral tolerance induction, while the role of Treg in the sensitization phase remained unclear. Ring et al. have recently reported that the administration of Treg suppressed the extent of sensitization in CHS by inhibiting DCs and CD8 T cells in the draining LNs [52]. In their report, Treg and DCs established a gap junctions, which caused a reduction in the capacity of DCs to stimulate CD8 T cells. In their next report, the same authors stated that Treg activation in draining LNs was mediated by ATP, because Treg acquired an activated phenotype upon ATP treatment in vitro, while blockage of ATP receptors on Treg abrogated ATP-mediated activation and suppressive function of Treg in vivo [53].

\section{c. The role of endogenous Treg in CHS}

As described above, exogenous administration of Treg suppresses CHS both in the sensitization phase and in the elicitation phase. It remains unclear, however, whether endogenous Treg play the same suppressive role under physiological conditions. To this end, specific depletion of Treg in vivo is required. Although $\mathrm{CD} 4{ }^{+} \mathrm{CD} 25^{+}$has been used as a marker for Treg, CD25 is expressed in activated CD4 cells as well as in Treg. Therefore, Foxp3 is a more definitive marker of Treg, but because Foxp3 is a transcriptional factor that exists intracellularly, the purification of live Treg or depletion by means of neutralizing $\mathrm{mAb}$ has been technically difficult. 
To solve these problems, Foxp3 reporter mice expressing human CD2 and human CD52 chimeric protein have been generated and designated as Foxp $3^{\mathrm{hCD} 2 / \mathrm{hCD} 52}$ mice. Since Foxp $3^{+}$cells co-express hCD2 on the cellular surface, live Foxp $3^{+}$Treg are sorted with anti-hCD2 mAb and depleted with neutralizing anti-hCD52 Ab [25]. The mice have been used in the investgations into the role of endogenous Treg in CHS. Depletion of Treg in the elicitation phase caused the ear swelling response to be enhanced and prolonged compared with that seen in the control, indicating that Treg is responsible for terminating skin inflammation in CHS [25].

In addition, the role and mobility of Treg in the skin during CHS was investigated. Kaede-transgenic mice are genetically engineered to ubiquitously express Kaede protein, a photoconvertible protein that changes its fluorescence from green to red under exposure to violet light. Therefore, mobility of cells from the skin under physiological conditions can be analyzed. Treg were found to localize abundantly in the inflamed skin seen in CHS, and these skin Treg were found to migrate further back to draining LNs. Treg from the skin showed significantly higher mRNA expression of $\mathrm{T}$ cell suppression-associated molecules such as IL-10, TGF- $\beta$ and CTLA4. Consistently, Treg from the skin exhibited significantly stronger suppressive activity both in vivo and in vitro (Figure 1). These results suggest that Treg in the skin also play important roles in the termination of dermatitis and possibly in the control of systemic immune responses.

It has been suggested that Treg in the skin contribute to its homeostasis, since chronic depletion of skin Treg leads to the development of spontaneous dermatitis [24] [26]. Schneider et al. have reported that CCR7-deficient mice showed a reduced number of Treg in draining LNs and an enhanced inflammatory response in CHS after repeated hapten application [54], which suggests the homing of Treg to draining LNs through 
CCR7 plays an important role in eliciting the function of Treg.

Endogenous Treg regulate the extent of sensitization as well as that of challenge in CHS. Depletion of Treg during the sensitization phase leads to enhanced skin inflammation [55]. Mice depleted with Treg population showed increased numbers of memory $\mathrm{T}$ cells and higher expression levels of costimulatory molecules in DCs in draining LNs compared with control mice, suggesting that endogenous Treg modulate DC function and thus regulate the extent of sensitization [55]. Recent findings on the role of Treg in CHS are summarized in Table 1, and schematic views of those findings are illustrated in Figures 3 and 4

\section{Atopic dermatitis (AD) and Treg}

Atopic dermatitis is one of the most common skin inflammatory disorders. New insights point to an important role of structural abnormalities in the epidermis combined with immune dysregulation [56]. Although studies on the role of Th2 cells have focused on the pathophysiology of $\mathrm{AD}$, recent reports have indicated the importance of other $\mathrm{T}$ cell subsets such as Th17 [57] and Treg.

Ou et al. [58] have compared the numbers and functionality of peripheral blood mononuclear cells (PBMC) between healthy controls and AD patients, and reported that AD patients have higher numbers of Treg, each with a suppressive activity comparable to that of Treg in healthy controls, in the peripheral blood. Others have also reported that increased numbers of Treg in the PBMC of AD patients [59] and expansion of Treg were positively associated with disease activity in $\mathrm{AD}$ [60]. On the other hand, it has also been reported that the numbers of Treg among the PBMC are similar between AD and healthy controls [61]. In AD skin lesions, it was initially reported that Treg were 
absent, while $\operatorname{Tr} 1$ were detected [62]. Later on, however, several groups reported the existence of Treg in AD skin lesions [63, 64]. Because AD is a chronic inflammatory disease with multiple disease stages and multiple factors, and because some treatments for AD such as cyclosporine [59, 61, 65], glucocoriticoids [33] and UV radiation [28], can alter the number of Treg in the PBMC, the interpretation and comparison of these studies will require careful attention.

Based on observations of IPEX syndrome patients, who show atopic-like dermatitis and high IgE levels, however, it seems probable that the number of Treg is related to the development of $\mathrm{AD}$ lesions [6]. As for the function of Treg in $\mathrm{AD}$, it has been reported that their suppressive activity is similar to that of Treg in healthy controls [58]. Reefer et al., however, have reported that a new subtype of Treg with Th2-promoting ability has been observed in $\mathrm{AD}$ and that its functions depend on the expression of CCR6 [66]. In this report, CCR6-negative CD25-high positive Treg produced Th2 cytokines, and co-culture with effector T cells selectively enhanced IL-5 production, suggesting the heterogeneity of Treg in AD.

Recently, dysfunction of Treg has been reported in psoriasis [67], another chronic inflammatory skin disease. Treg in both lesional skin and blood from psoriasis patients showed reduced suppressive activity [67], and such dysfunction was dependent on the signaling from IL-6, which was abundantly produced in psoriasis lesion [68]. Local cytokine milieu in AD may also alter the function of Treg in AD skin.

\section{Conclusion}

We have reviewed the roles of Treg in cutaneous immune responses. A considerable 
amount of knowledge on Treg has been accumulated, and multiple mechanisms and various molecules are reported to be involved in Treg-mediated immunosuppression. It is likely that the suppressive mechanisms of Treg may differ depending on disease stage and the skin immune response type. Analysis using Foxp3-diphtheria toxin receptor knockin mice or Foxp $3^{\mathrm{hCD} 2 / \mathrm{hCD} 52}$ mice, which enable us to deplete Treg conditionally and specifically, will further reveal the molecular mechanisms and physiological functions of Treg in cutaneous immune responses.

It is crucially important to clarify how and to what extent those molecules are involved in Treg function in humans. From a clinical perspective, the precise mechanism by which Treg function in the elicitation phase is an important issue to be addressed, since most patients with cutaneous immune disease have already been sensitized. We expect that further effort in the investigation of Treg will give us important clues supporting the development of innovative therapeutic approaches for various skin diseases.

\section{Acknowledgements}

This study was supported in part by grants from the Ministry of Education, Culture, Sports, Science, and Technology of Japan, and the Ministry of Health, Labor, and Welfare of Japan.

\section{Figure legends}




\section{Figure1. Possible mechanisms involved in suppression by Treg}

(a) Soluble factor-dependent mechanisms. Treg produce large amounts of IL-10, IL-35, and TGF-beta, all of which suppress naive/effector $\mathrm{T}$ cell activation. Treg also absorb IL-2, which causes cytokine deprivation-induced apoptosis among effector T cells. (b) Contact-dependent mechanisms. CTLA-4 on Treg deliver negative signals to $\mathrm{T}$ cells. CD39/CD73 on Treg catalyze ATP and generate pericellular adenosine, exerting an anti-inflammatory effect. Treg also may kill responder $\mathrm{T}$ cells by a granzyme or perforin-dependent mechanisms. (c) Indirect mechanisms. Treg inhibit the interaction between DCs and effector T cells. Treg also downregulate DC activation and thus cause immunosuppression.

\section{Figure 2. Proposed mechanism of Treg induction by skin DCs}

UV exposure or skin grafting induces RANKL expression on keratinocytes, which stimulate LCs. RANKL-stimulated LCs then induce Treg in draining LNs. Under conditions of UV exposure, it has also been proposed that the UV-induced Treg affect DCs and modify their functions from a stimulatory phenotype to a regulatory phenotype, which further induces Treg. In addition to LCs, CD103-negative dermal DCs can induce Treg in draining LNs.

\section{Figure 3. Possible mechanism of suppression by Treg in sensitization phase of CHS} Treg are activated in draining LNs by ATP. They down-regulate DC activation through gap junction formation and subsequent $\mathrm{T}$ cell proliferation, which controls the extent of sensitization. 


\section{Figure 4. Possible mechanism of suppression by Treg in elicitation phase of CHS}

Treg suppress effector T cells in the LNs and inhibit leukocyte influx into the periphery through IL-10 or CD39-dependent mechanisms. In addition, Treg migrating into the skin could suppress the effector T cell functions in the skin. Furthermore, a fraction of Treg in the skin migrate back to the draining LNs through afferent lymphatic vessels, and can return from there to the skin. These skin-derived Treg possess higher suppression activity than LN-resident Treg, and contribute to the termination of skin inflammation. 
Table 1. An overview of recently published papers about Treg and CHS

Major findings

Reference

Attenuated sensitization by Treg induced by RANKL-activated LC

in a UV-immunosuppression model

Sensitization Attenuated sensitization by Treg induced by IL-10 from

RANKL-activated LC in a skin graft immunosuppression model

Attenuated sensitization by Treg induced by orally administered

antigen in an oral tolerance model

Treg attenuate sensitization by modifying DC function through gap

junction formation

Treg acquire an activated phenotype by means of ATP in draining

LNs

Enhanced ear swelling response resulting from the depletion of endogenous Treg

Reduced ear swelling response resulting from the inhibition of the

leukocyte influx through IL-10 from Treg

Elicitation Reduced ear swelling response resulting from the inhibition of the

[50]

leukocyte influx through adenosine from Treg via CD39/CD73

(inhibition of E- and P-selectin expression in endothelial cells)

Treg acquire activated phenotype by means of ATP in blood.

Enhanced and prolonged ear swelling response resulting from

depletion of endogenous Treg 


\section{Reference}

[1] Sakaguchi S, Sakaguchi N, Asano M, Itoh M, Toda M: Immunologic self-tolerance maintained by activated T cells expressing IL-2 receptor alpha-chains (CD25).

Breakdown of a single mechanism of self-tolerance causes various autoimmune diseases. J Immunol 155: 1151-1164, 1995.

[2] Sakaguchi S, Toda M, Asano M, Itoh M, Morse SS, Sakaguchi N: T cell-mediated maintenance of natural self-tolerance: its breakdown as a possible cause of various autoimmune diseases. J Autoimmun 9: 211-220, 1996.

[3] Hori S, Nomura T, Sakaguchi S: Control of regulatory T cell development by the transcription factor Foxp3. Science 299: 1057-1061, 2003.

[4] Sakaguchi S, Yamaguchi T, Nomura T, Ono M: Regulatory T cells and immune tolerance. Cell 133: 775-787, 2008.

[5] Brunkow ME, Jeffery EW, Hjerrild KA, Paeper B, Clark LB, Yasayko SA, et al.: Disruption of a new forkhead/winged-helix protein, scurfin, results in the fatal lymphoproliferative disorder of the scurfy mouse. Nat Genet 27: 68-73, 2001. [6] Ochs HD, Ziegler SF, Torgerson TR: FOXP3 acts as a rheostat of the immune response. Immunol Rev 203: 156-164, 2005.

[7] Benson MJ, Pino-Lagos K, Rosemblatt M, Noelle RJ: All-trans retinoic acid mediates enhanced $\mathrm{T}$ reg cell growth, differentiation, and gut homing in the face of high levels of co-stimulation. J Exp Med 204: 1765-1774, 2007.

[8] Mucida D, Park Y, Kim G, Turovskaya O, Scott I, Kronenberg M, et al.: Reciprocal TH17 and regulatory T cell differentiation mediated by retinoic acid. Science 317: 256-260, 2007. 
[9] Vieira PL, Christensen JR, Minaee S, O'Neill EJ, Barrat FJ, Boonstra A, et al.:

IL-10-secreting regulatory T cells do not express Foxp3 but have comparable regulatory function to naturally occurring CD4+CD25+ regulatory T cells. J Immunol 172: 5986-5993, 2004.

[10] Groux H, O'Garra A, Bigler M, Rouleau M, Antonenko S, de Vries JE, et al.: A CD4+ T-cell subset inhibits antigen-specific T-cell responses and prevents colitis. Nature 389: 737-742, 1997.

[11] Suri-Payer E, Cantor H: Differential cytokine requirements for regulation of autoimmune gastritis and colitis by CD4(+)CD25(+) T cells. J Autoimmun 16: 115-123, 2001.

[12] Furtado GC, Olivares-Villagomez D, Curotto de Lafaille MA, Wensky AK, Latkowski JA, Lafaille JJ: Regulatory T cells in spontaneous autoimmune encephalomyelitis. Immunol Rev 182: 122-134, 2001.

[13] Asseman C, Mauze S, Leach MW, Coffman RL, Powrie F: An essential role for interleukin 10 in the function of regulatory $\mathrm{T}$ cells that inhibit intestinal inflammation. $\mathrm{J}$ Exp Med 190: 995-1004, 1999.

[14] Tang Q, Adams JY, Tooley AJ, Bi M, Fife BT, Serra P, et al.: Visualizing regulatory $\mathrm{T}$ cell control of autoimmune responses in nonobese diabetic mice. Nat Immunol 7: 83-92, 2006.

[15] Nakamura K, Kitani A, Strober W: Cell contact-dependent immunosuppression by CD4(+)CD25(+) regulatory T cells is mediated by cell surface-bound transforming growth factor beta. J Exp Med 194: 629-644, 2001.

[16] Collison LW, Workman CJ, Kuo TT, Boyd K, Wang Y, Vignali KM, et al.: The inhibitory cytokine IL-35 contributes to regulatory T-cell function. Nature 450: 566-569, 
2007.

[17] Pandiyan P, Zheng L, Ishihara S, Reed J, Lenardo MJ: CD4+CD25+Foxp3+ regulatory $\mathrm{T}$ cells induce cytokine deprivation-mediated apoptosis of effector CD4+ T cells. Nat Immunol 8: 1353-1362, 2007.

[18] Deaglio S, Dwyer KM, Gao W, Friedman D, Usheva A, Erat A, et al.: Adenosine generation catalyzed by CD39 and CD73 expressed on regulatory T cells mediates immune suppression. J Exp Med 204: 1257-1265, 2007.

[19] Gondek DC, Lu LF, Quezada SA, Sakaguchi S, Noelle RJ: Cutting edge: contact-mediated suppression by $\mathrm{CD} 4+\mathrm{CD} 25+$ regulatory cells involves a granzyme B-dependent, perforin-independent mechanism. J Immunol 174: 1783-1786, 2005. [20] Onishi Y, Fehervari Z, Yamaguchi T, Sakaguchi S: Foxp3+ natural regulatory T cells preferentially form aggregates on dendritic cells in vitro and actively inhibit their maturation. Proc Natl Acad Sci U S A 105: 10113-10118, 2008.

[21] Tadokoro CE, Shakhar G, Shen S, Ding Y, Lino AC, Maraver A, et al.: Regulatory T cells inhibit stable contacts between CD4+ T cells and dendritic cells in vivo. J Exp Med 203: 505-511, 2006.

[22] Grohmann U, Orabona C, Fallarino F, Vacca C, Calcinaro F, Falorni A, et al.: CTLA-4-Ig regulates tryptophan catabolism in vivo. Nat Immunol 3: 1097-1101, 2002. [23] Gri G, Piconese S, Frossi B, Manfroi V, Merluzzi S, Tripodo C, et al.: CD4+CD25+ regulatory $\mathrm{T}$ cells suppress mast cell degranulation and allergic responses through OX40-OX40L interaction. Immunity 29: 771-781, 2008.

[24] Sather BD, Treuting P, Perdue N, Miazgowicz M, Fontenot JD, Rudensky AY, et al.: Altering the distribution of Foxp3(+) regulatory T cells results in tissue-specific inflammatory disease. J Exp Med 204: 1335-1347, 2007. 
[25] Tomura M, Honda T, Tanizaki H, Otsuka A, Egawa G, Tokura Y, et al.: Activated regulatory $\mathrm{T}$ cells are the major $\mathrm{T}$ cell type emigrating from the skin during a cutaneous immune response in mice. J Clin Invest.

[26] Dudda JC, Perdue N, Bachtanian E, Campbell DJ: Foxp3+ regulatory T cells maintain immune homeostasis in the skin. J Exp Med 205: 1559-1565, 2008.

[27] Yurchenko E, Tritt M, Hay V, Shevach EM, Belkaid Y, Piccirillo CA:

CCR5-dependent homing of naturally occurring CD4+ regulatory T cells to sites of Leishmania major infection favors pathogen persistence. J Exp Med 203: 2451-2460, 2006.

[28] Loser K, Beissert S: Regulation of cutaneous immunity by the environment: an important role for UV irradiation and vitamin D. Int Immunopharmacol 9: 587-589, 2009.

[29] Loser K, Mehling A, Loeser S, Apelt J, Kuhn A, Grabbe S, et al.: Epidermal RANKL controls regulatory T-cell numbers via activation of dendritic cells. Nat Med 12: 1372-1379, 2006.

[30] Schwarz A, Noordegraaf M, Maeda A, Torii K, Clausen BE, Schwarz T:

Langerhans cells are required for UVR-induced immunosuppression. J Invest Dermatol 130: 1419-1427.

[31] Yoshiki R, Kabashima K, Sakabe J, Sugita K, Bito T, Nakamura M, et al.: The mandatory role of IL-10-producing and OX40 ligand-expressing mature Langerhans cells in local UVB-induced immunosuppression. J Immunol 184: 5670-5677. [32] Yoshiki R, Kabashima K, Sugita K, Atarashi K, Shimauchi T, Tokura Y: IL-10-producing Langerhans cells and regulatory T cells are responsible for depressed contact hypersensitivity in grafted skin. J Invest Dermatol 129: 705-713, 2009. 
[33] Stary G, Klein I, Bauer W, Koszik F, Reininger B, Kohlhofer S, et al.:

Glucocorticosteroids modify Langerhans cells to produce TGF-beta and expand regulatory T cells. J Immunol 186: 103-112.

[34] Schwarz A, Maeda A, Wild MK, Kernebeck K, Gross N, Aragane Y, et al.: Ultraviolet radiation-induced regulatory $\mathrm{T}$ cells not only inhibit the induction but can suppress the effector phase of contact hypersensitivity. J Immunol 172: 1036-1043, 2004.

[35] Schwarz A, Maeda A, Schwarz T: Alteration of the migratory behavior of UV-induced regulatory T cells by tissue-specific dendritic cells. J Immunol 178: 877-886, 2007.

[36] Schwarz A, Schwarz T: UVR-induced regulatory T cells switch antigen-presenting cells from a stimulatory to a regulatory phenotype. J Invest Dermatol 130: 1914-1921. [37] Wang L, Jameson SC, Hogquist KA: Epidermal Langerhans cells are not required for UV-induced immunosuppression. J Immunol 183: 5548-5553, 2009.

[38] Guilliams M, Crozat K, Henri S, Tamoutounour S, Grenot P, Devilard E, et al.: Skin-draining lymph nodes contain dermis-derived CD103- dendritic cells that constitutively produce retinoic acid and induce Foxp3+ regulatory T cells. Blood. [39] Sun CM, Hall JA, Blank RB, Bouladoux N, Oukka M, Mora JR, et al.: Small intestine lamina propria dendritic cells promote de novo generation of Foxp3 T reg cells via retinoic acid. J Exp Med 204: 1775-1785, 2007.

[40] Grabbe S, Schwarz T: Immunoregulatory mechanisms involved in elicitation of allergic contact hypersensitivity. Immunol Today 19: 37-44, 1998.

[41] Randolph GJ, Ochando J, Partida-Sanchez S: Migration of dendritic cell subsets and their precursors. Annu Rev Immunol 26: 293-316, 2008. 
[42] Kabashima K, Shiraishi N, Sugita K, Mori T, Onoue A, Kobayashi M, et al.:

CXCL12-CXCR4 engagement is required for migration of cutaneous dendritic cells. Am J Pathol 171: 1249-1257, 2007.

[43] Nagamachi M, Sakata D, Kabashima K, Furuyashiki T, Murata T, Segi-Nishida E, et al.: Facilitation of Th1-mediated immune response by prostaglandin E receptor EP1. J Exp Med 204: 2865-2874, 2007.

[44] Nakae S, Komiyama Y, Nambu A, Sudo K, Iwase M, Homma I, et al.:

Antigen-specific T cell sensitization is impaired in IL-17-deficient mice, causing suppression of allergic cellular and humoral responses. Immunity 17: 375-387, 2002. [45] McHale JF, Harari OA, Marshall D, Haskard DO: Vascular endothelial cell expression of ICAM-1 and VCAM-1 at the onset of eliciting contact hypersensitivity in mice: evidence for a dominant role of TNF-alpha. J Immunol 162: 1648-1655, 1999. [46] Tietz W, Allemand Y, Borges E, von Laer D, Hallmann R, Vestweber D, et al.: CD4+ T cells migrate into inflamed skin only if they express ligands for E- and P-selectin. J Immunol 161: 963-970, 1998.

[47] Hirata T, Merrill-Skoloff G, Aab M, Yang J, Furie BC, Furie B: P-Selectin glycoprotein ligand 1 (PSGL-1) is a physiological ligand for E-selectin in mediating T helper 1 lymphocyte migration. J Exp Med 192: 1669-1676, 2000.

[48] Mori T, Kabashima K, Yoshiki R, Sugita K, Shiraishi N, Onoue A, et al.: Cutaneous hypersensitivities to hapten are controlled by IFN-gamma-upregulated keratinocyte Th1 chemokines and IFN-gamma-downregulated langerhans cell Th2 chemokines. J Invest Dermatol 128: 1719-1727, 2008.

[49] Ring S, Schafer SC, Mahnke K, Lehr HA, Enk AH: CD4+ CD25+ regulatory T cells suppress contact hypersensitivity reactions by blocking influx of effector T cells 
into inflamed tissue. Eur J Immunol 36: 2981-2992, 2006.

[50] Ring S, Oliver SJ, Cronstein BN, Enk AH, Mahnke K: CD4+CD25+ regulatory T cells suppress contact hypersensitivity reactions through a CD39, adenosine-dependent mechanism. J Allergy Clin Immunol 123: 1287-1296 e1282, 2009.

[51] Dubois B, Chapat L, Goubier A, Papiernik M, Nicolas JF, Kaiserlian D: Innate $\mathrm{CD} 4+\mathrm{CD} 25+$ regulatory $\mathrm{T}$ cells are required for oral tolerance and inhibition of CD8+ $\mathrm{T}$ cells mediating skin inflammation. Blood 102: 3295-3301, 2003.

[52] Ring S, Karakhanova S, Johnson T, Enk AH, Mahnke K: Gap junctions between regulatory T cells and dendritic cells prevent sensitization of CD8(+) T cells. J Allergy Clin Immunol 125: 237-246 e231-237.

[53] Ring S, Enk AH, Mahnke K: ATP activates regulatory T Cells in vivo during contact hypersensitivity reactions. J Immunol 184: 3408-3416.

[54] Schneider MA, Meingassner JG, Lipp M, Moore HD, Rot A: CCR7 is required for the in vivo function of CD4+ CD25+ regulatory T cells. J Exp Med 204: 735-745, 2007. [55] Honda T, Otsuka A, Tanizaki H, Minegaki Y, Nagao K, Waldmann H, et al.: Enhanced murine contact hypersensitivity by depletion of endogenous regulatory $\mathrm{T}$ cells in the sensitization phase. J Dermatol Sci.

[56] Boguniewicz M, Leung DY: Recent insights into atopic dermatitis and implications for management of infectious complications. J Allergy Clin Immunol 125: 4-13; quiz 14-15.

[57] Koga C, Kabashima K, Shiraishi N, Kobayashi M, Tokura Y: Possible pathogenic role of Th17 cells for atopic dermatitis. J Invest Dermatol 128: 2625-2630, 2008. [58] Ou LS, Goleva E, Hall C, Leung DY: T regulatory cells in atopic dermatitis and subversion of their activity by superantigens. J Allergy Clin Immunol 113: 756-763, 
2004.

[59] Hijnen D, Haeck I, van Kraats AA, Nijhuis E, de Bruin-Weller MS, Bruijnzeel-Koomen CA, et al.: Cyclosporin A reduces CD4(+)CD25(+) regulatory T-cell numbers in patients with atopic dermatitis. J Allergy Clin Immunol 124: 856-858, 2009.

[60] Ito Y, Adachi Y, Makino T, Higashiyama H, Fuchizawa T, Shimizu T, et al.: Expansion of FOXP3-positive CD4+CD25+ T cells associated with disease activity in atopic dermatitis. Ann Allergy Asthma Immunol 103: 160-165, 2009.

[61] Brandt C, Pavlovic V, Radbruch A, Worm M, Baumgrass R: Low-dose cyclosporine A therapy increases the regulatory $\mathrm{T}$ cell population in patients with atopic dermatitis. Allergy 64: 1588-1596, 2009.

[62] Verhagen J, Akdis M, Traidl-Hoffmann C, Schmid-Grendelmeier P, Hijnen D, Knol EF, et al.: Absence of T-regulatory cell expression and function in atopic dermatitis skin. J Allergy Clin Immunol 117: 176-183, 2006.

[63] Schnopp C, Rad R, Weidinger A, Weidinger S, Ring J, Eberlein B, et al.: Fox-P3-positive regulatory $\mathrm{T}$ cells are present in the skin of generalized atopic eczema patients and are not particularly affected by medium-dose UVA1 therapy.

Photodermatol Photoimmunol Photomed 23: 81-85, 2007.

[64] Caproni M, Torchia D, Antiga E, Volpi W, del Bianco E, Fabbri P: The effects of tacrolimus ointment on regulatory $\mathrm{T}$ lymphocytes in atopic dermatitis. J Clin Immunol 26: 370-375, 2006.

[65] Baumgrass R, Brandt C, Wegner F, Abdollahnia M, Worm M: Low-dose, but not high-dose, cyclosporin A promotes regulatory T-cell induction, expansion, or both. $\mathrm{J}$ Allergy Clin Immunol 126: 183-184; author reply 184. 
[66] Reefer AJ, Satinover SM, Solga MD, Lannigan JA, Nguyen JT, Wilson BB, et al.: Analysis of CD25hiCD4+ "regulatory" T-cell subtypes in atopic dermatitis reveals a novel T(H)2-like population. J Allergy Clin Immunol 121: 415-422 e413, 2008.

[67] Sugiyama H, Gyulai R, Toich E, Garacxi E, Stevens SR, McComick TS, et al.: Dysfunctional Blood and Target Tissue CD4 CD25high Regulatory T Cells in Psoriasis: Mechanism Underlying Unrestrained Pathogenic Effector T Cell Proliferation. J Immunol 174: 164-173, 2005.

[68] Sugiyama H, Gyulai R, Toich E, Garacxi E, Stevens SR, McComick TS, et al.: IL-6 Signaling in Psoriasis Prevents Immune Suppression by Regulatory T Cells. J Immunol 183: 3170-3176, 2009. 
a. Soluble factor-dependent mechanisms

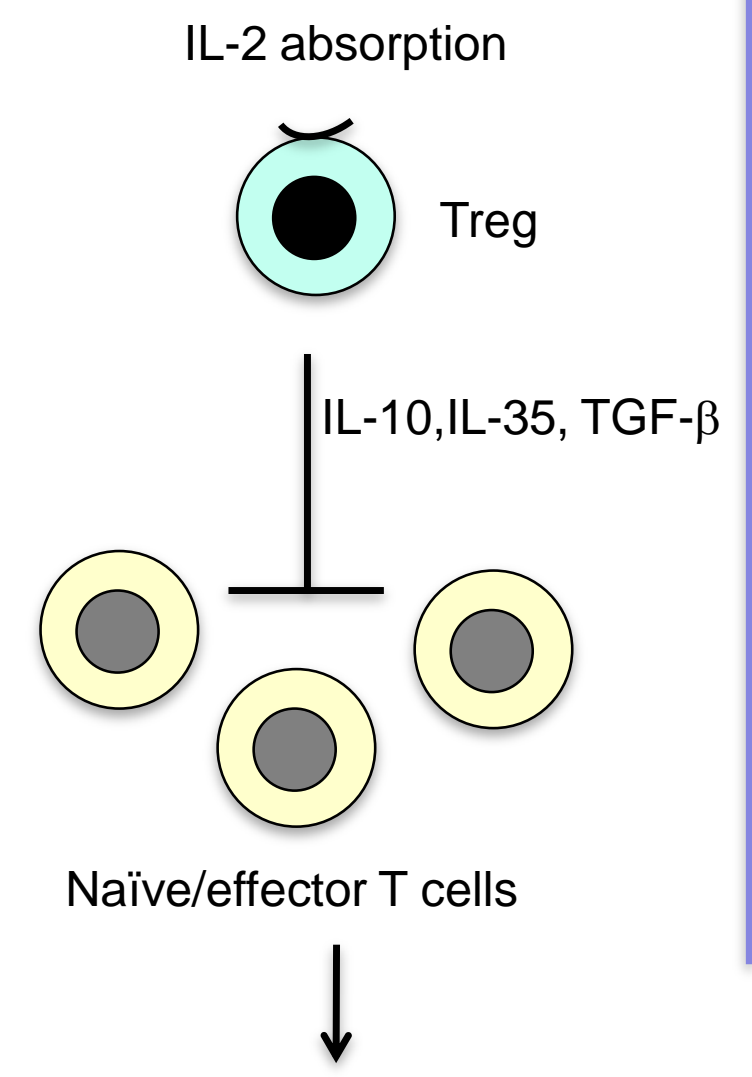

Suppression of T cell activation b. Contact-dependent mechanisms

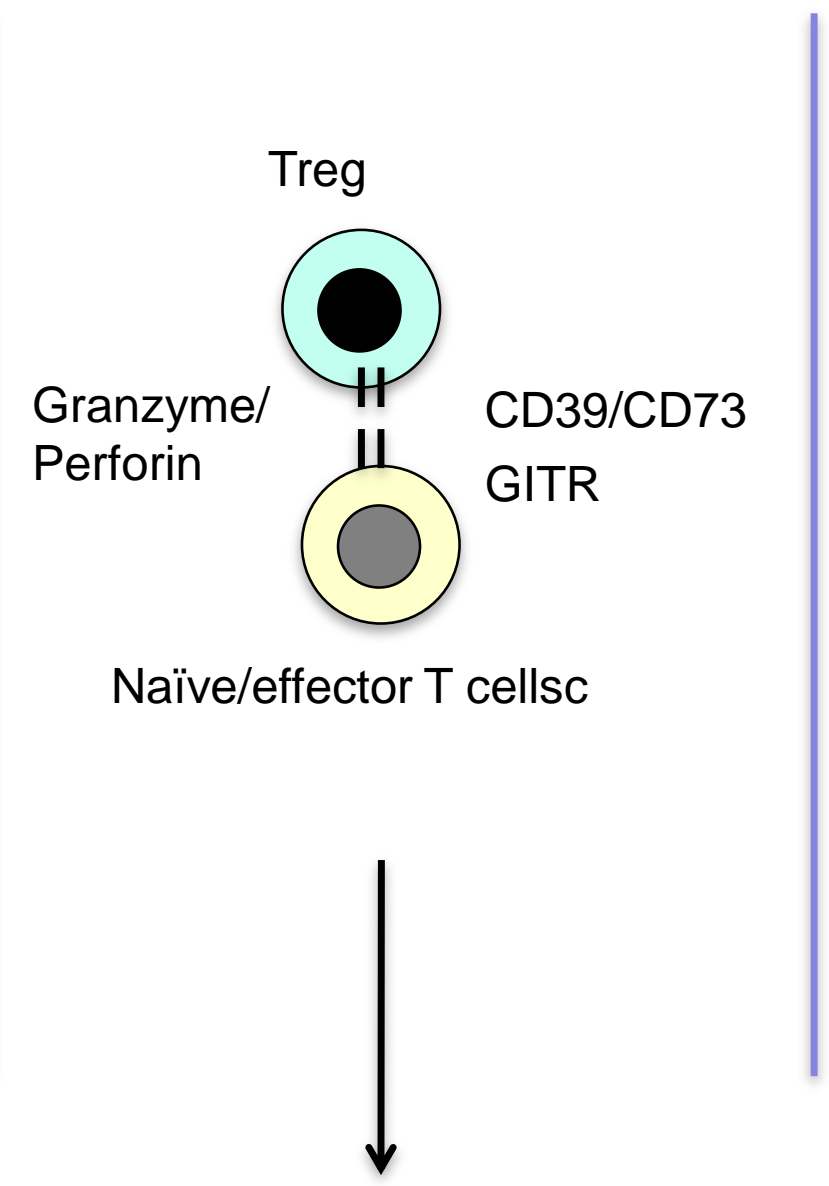

Killing/delivering a negative signal to T cells c. Indirect mechanisms involving both soluble and contactdependent factors

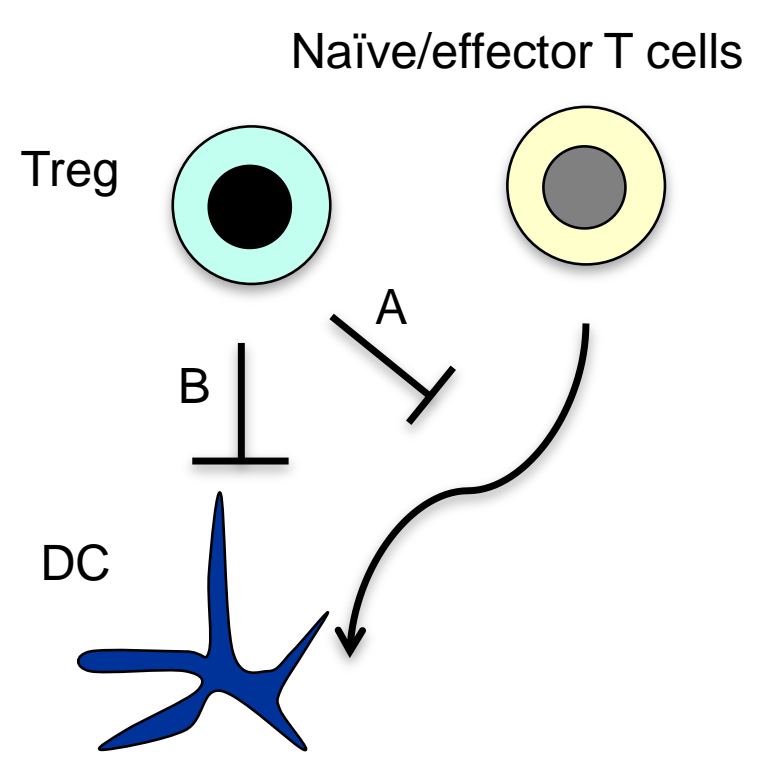

A: Outcompeting effector T cells for interaction with DCs (LFA-1)

B: Modifying DC function

1.Downregulating co-stimulatory molecule (CTLA-4/IL-10///TGF- $\beta$ ) 2.Stimulating $D C s$ to express IDO 
UVB, skin grafting

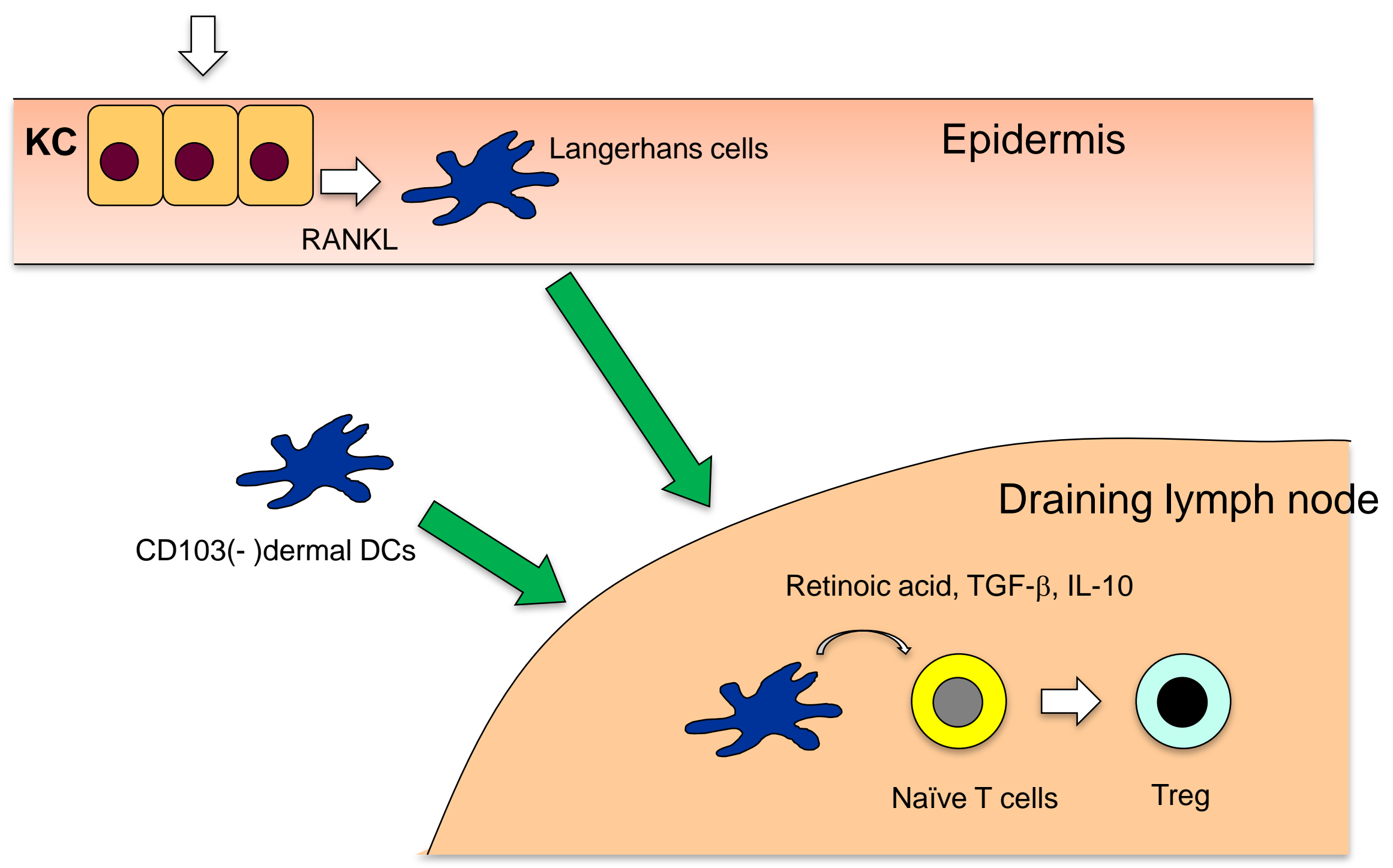




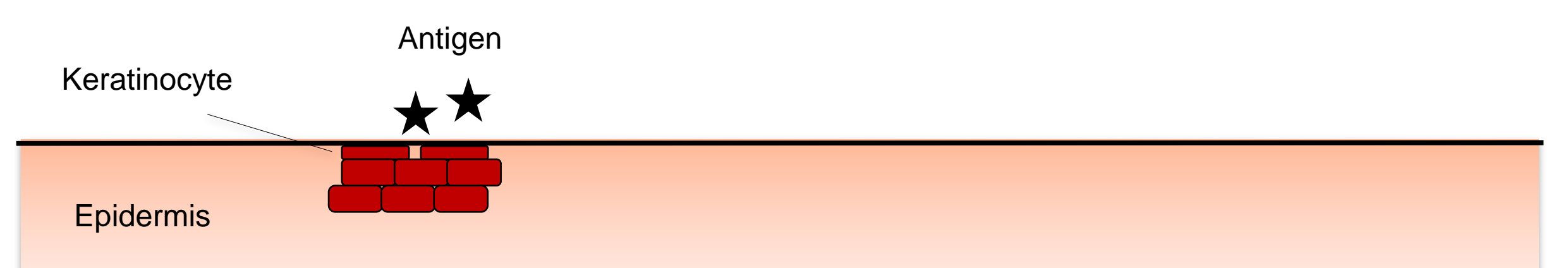

\section{Dermis}
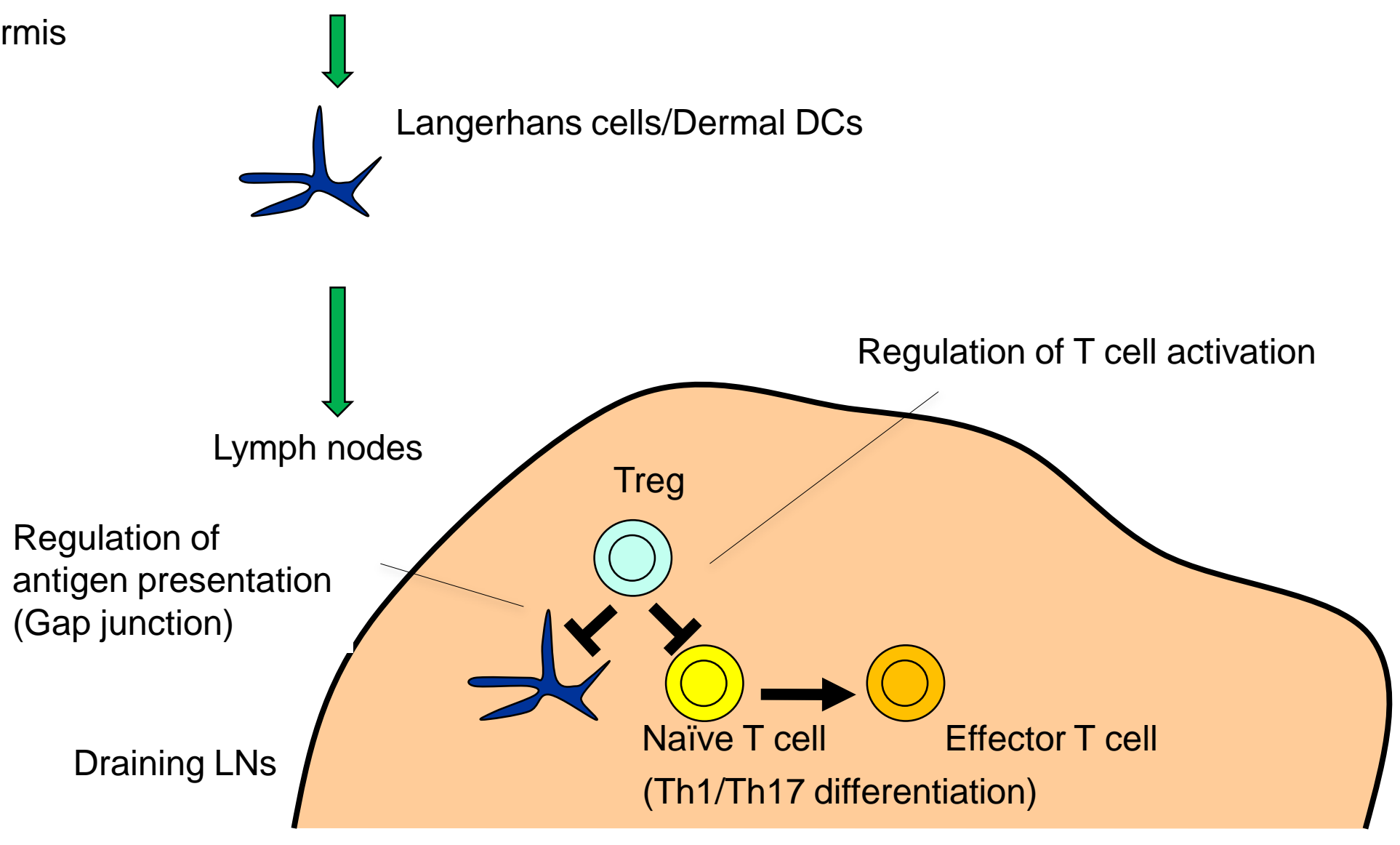


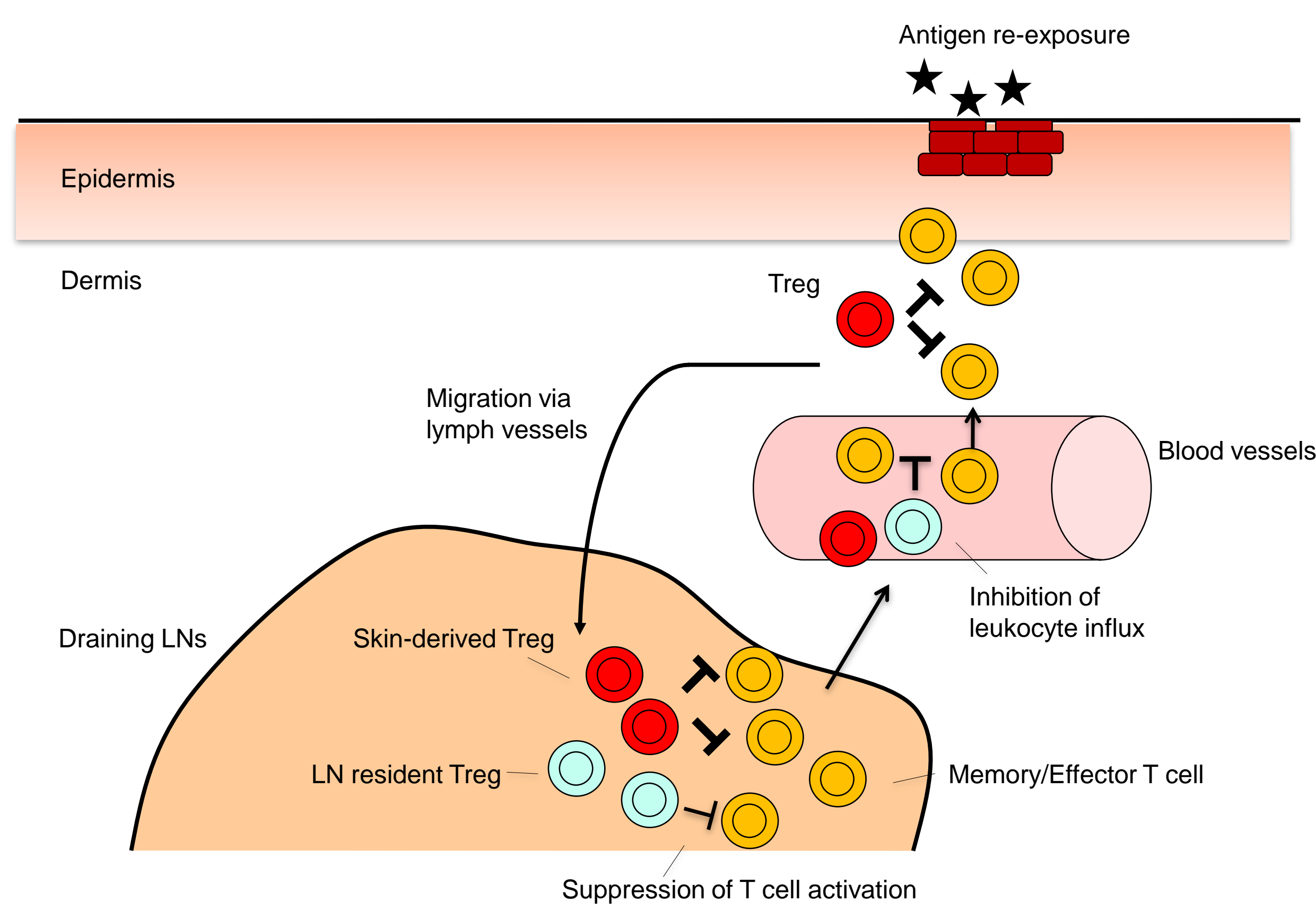

